Bangladesh J. Sci. Ind. Res. 42(2), 105-114, 2007

\title{
Growth Phenomena of Carbon Nanotubes Over Co-Mo/MgO Catalyst from the Decomposition of Acetylene
}

\author{
Md. Shajahan ${ }^{a}$ and A. K. M. Fazle Kibria ${ }^{b}$ \\ aSchool of Chemical Engineering and Technology, Chonbuk National University, \\ Chonju 561-756, Republic of Korea and ${ }^{\mathrm{b} C h e m i s t r y ~ D i v i s i o n, ~ A t o m i c ~ E n e r g y ~ C e n t r e, ~}$ \\ P. O. Box 164, Ramna, Dhaka-1000, Bangladesh
}

\begin{abstract}
Carbon nanotubes (CNTs) were grown over 12Mo:18Co:70MgO catalyst at 500, 700 and $900^{\circ} \mathrm{C}$ from $\mathrm{C}_{2} \mathrm{H}_{2}$ decomposition for 30 minutes using chemical vapor deposition (CVD) method. The highest yield of CNTs was observed at $700^{\circ} \mathrm{C}$. The lowest diameter of CNTs appeared at $900^{\circ} \mathrm{C}$. Quadruple mass spectroscopy (QMS) study on the species generated from the catalytic decomposition of $\mathrm{C}_{2} \mathrm{H}_{2}$ identified that the catalyst consumed $\mathrm{C}$ species during the growth stage of CNTs. The consumption period of $\mathrm{C}$ varied with temperature and showed a close relationship with the carbon yield. At 500, 700 and $900^{\circ} \mathrm{C}$, the consumption periods were 12,35 and $20 \mathrm{~min}$, respectively, and the corresponding carbon yields were 7, 385 and $89 \%$. From the XRD analysis of catalyst surface, and XRD and Raman analysis of the CNTs, it was realized that Co particles released from $\mathrm{Co}_{3} \mathrm{O}_{4}, \mathrm{CoMoO}_{4}$ and $\mathrm{CoO}-\mathrm{MgO}$ were participated in CNTs growth at 500, 700 and $900^{\circ} \mathrm{C}$, respectively. The Co particles acted as the transporting medium of carbon to grow CNTs. The tubes are MWNTs and grown by tip growth mode.
\end{abstract}

\section{Introduction}

The demand of carbon nanotubes (CNTs) is going high because of their application possibilities as field emission displays (Saito et al. 2002, Yu et al. 2003), battery electrode (Frackowiak et al. 1999), capacitors (Chatterjee et al. 2003), hydrogen storage material (Ci et al. 2003), hydrogen evolution material (Prosini et al. 2003), etc. To fulfill this demand, it requires large-scale produc- tion of CNTs. For large-scale production of CNTs, it is necessary to improve catalysts further with a better understanding of the role of catalysts and reactants during CNTs growth. In general, the species generated during the catalytic decomposition of hydrocarbon play an important role during the growth of CNTs (Otsuka et al. 2001, Lee et al. 2003). 
Recently, Mo containing bimetallic supported catalysts such as Mo-Fe: $\mathrm{Al}_{2} \mathrm{O}_{3}$ and Co$\mathrm{Mo}: \mathrm{SiO}_{2}$ are found effective in producing good amount of CNTs from $\mathrm{CH}_{4}, \mathrm{C}_{2} \mathrm{H}_{4}$ and CO decomposition (Hafner et al. 1998, Herrera et al. 2001). However, reports on the reactive species generated during their decomposition and proof of their consumption during CNTs growth are rarely available. Support such as $\mathrm{MgO}$ can form solid solution with transition metals like $\mathrm{Ni}, \mathrm{Co}$ and $\mathrm{Fe}$ whereas $\mathrm{SiO}_{2}$ has no such a capability. So, it can be expected that the amount of exposed active metal on the catalyst surface and the size of metal particle should vary with changing the support. It seems essential to clear the role of $\mathrm{MgO}$ in exposing the metals on the catalyst in favor of CNTs growth and concurrently the roles of Mo and Co in producing CNTs.

Considering above importance, the present program has been taken to prepare a Co$\mathrm{Mo} / \mathrm{MgO}$ catalyst, and to investigate the capability of the catalyst in growing CNTs from decomposition of $\mathrm{C}_{2} \mathrm{H}_{2}$ at different temperatures. Attempt was taken to identify and measure the species produced during catalytic decomposition of acetylene to explore the species responsible for the growth of CNTs. The study also attempted to explore fundamentally the potential roles of Mo and Co in the catalyst for large-scale growth of CNTs.

\section{Materials and Methods}

A bimetallic supported catalyst of weight compositions 12Mo:18Co:70MgO was pre- pared by impregnation method. To prepare the catalyst, alcoholic solutions of $\left(\mathrm{NH}_{4}\right)_{6} \mathrm{Mo}_{7} \mathrm{O}_{24} \cdot 4 \mathrm{H}_{2} \mathrm{O}$ and $\mathrm{Co}\left(\mathrm{NO}_{3}\right)_{2} \cdot 6 \mathrm{H}_{2} \mathrm{O}$ salts were slowly mixed with support $\mathrm{MgO}$ powder and stirred at $70^{\circ} \mathrm{C}$ to achieve a homogeneous mixture of metals and the support. The mixture was then dried at $100^{\circ} \mathrm{C}$ for $12 \mathrm{~h}$. The dry product was then calcined at $400^{\circ} \mathrm{C}$ for $6 \mathrm{~h}$ in a box furnace and reduced in $100 \mathrm{sccm} \mathrm{H}_{2}$ flow at $450^{\circ} \mathrm{C}$ for 4 $\mathrm{h}$ under vacuum. To understand the surface condition of the catalyst, XRD study was carried out. Then the catalyst was subjected to synthesize CNTs.

Approximately $0.2 \mathrm{~g}$ of the catalyst was uniformly dispersed in an alumina boat and placed in the central region of a horizontal quartz tube reactor of diameter $6.5 \mathrm{~cm}$ and length $18 \mathrm{~cm}$. There, the catalyst was activated at $500^{\circ} \mathrm{C}$ for $1 \mathrm{~h}$ under $100 \mathrm{sccm} \mathrm{H}_{2}$ flow and then the growth of CNTs was carried out. CNTs were grown at 500,700 and $900^{\circ} \mathrm{C}$ by flowing $\mathrm{C}_{2} \mathrm{H}_{2}: \mathrm{H}_{2}$ mixture of $10: 100 \mathrm{sccm}$ for $30 \mathrm{~min}$. Carbon yields were calculated using the procedure described earlier (Kibria et al. 2001).

The decomposition of $\mathrm{C}_{2} \mathrm{H}_{2}$ over the catalyst was investigated at 500, 700 and $900^{\circ} \mathrm{C}$ using a quadruple mass spectrometer (QMS) directly connecting to the reactor. The species produced from $\mathrm{C}_{2} \mathrm{H}_{2}$ in the range of $\mathrm{m} / \mathrm{e}$ value of 1 to 48 was scanned at $1 \mathrm{~s}$ interval. Variation of partial pressure of $\mathrm{C}_{2} \mathrm{H}_{2}$ species and $\mathrm{C}$ species as a function of time was determined. The structure and morphol- 
ogy of the grown CNTs were studied by scanning electron microscopy (SEM), Raman spectroscopy and X-ray diffraction (XRD).

\section{Results and Discussion}

Figures 1(a)-(c) show the scanning electron microscopy (SEM) images of the CNTs grown over $12 \mathrm{Mo}: 18 \mathrm{Co}: 70 \mathrm{MgO}$ catalyst for $30 \mathrm{~min}$ at 500,700 and $900^{\circ} \mathrm{C}$, respectively. It can be seen that the highest density of tubes of average diameter $40 \mathrm{~nm}$ were grown at $700^{\circ} \mathrm{C}$ whereas the lowest density of tubes of average diameter $60 \mathrm{~nm}$ were grown at $500^{\circ} \mathrm{C}$. The tubes grown at $900^{\circ} \mathrm{C}$ have diameter of about $20 \mathrm{~nm}$. This finding informs that the diameter of tubes gradually decreased with increasing the growth temperature. Such a growth behavior of CNTs may appear due to the decrease in active metal crystallites size with increasing temperature. The size of metal crystallites is a crucial factor for the growth of CNTs (Kibria et al. 2001, Yudasaka et al. 1997).

At 500, 700 and $900^{\circ} \mathrm{C}$, the observed carbon yields are 7, 385 and $89 \%$, respectively. It is notable that carbon yield was calculated using the formula: [Carbon yield $(\%)=\left\{\left(\mathrm{m}_{\mathrm{tot}}\right.\right.$ $\left.\left.-\mathrm{m}_{\text {cat }}\right) / \mathrm{m}_{\text {cat }}\right\} \times 100$ ], where mcat is the weight of the catalyst before CNTs growth and mtot is the total weight of the catalyst and CNTs after the growth of CNTs (Kibria et al. 2001). It indicates that carbon yield (\%) increased 55 folds with increasing temperature from
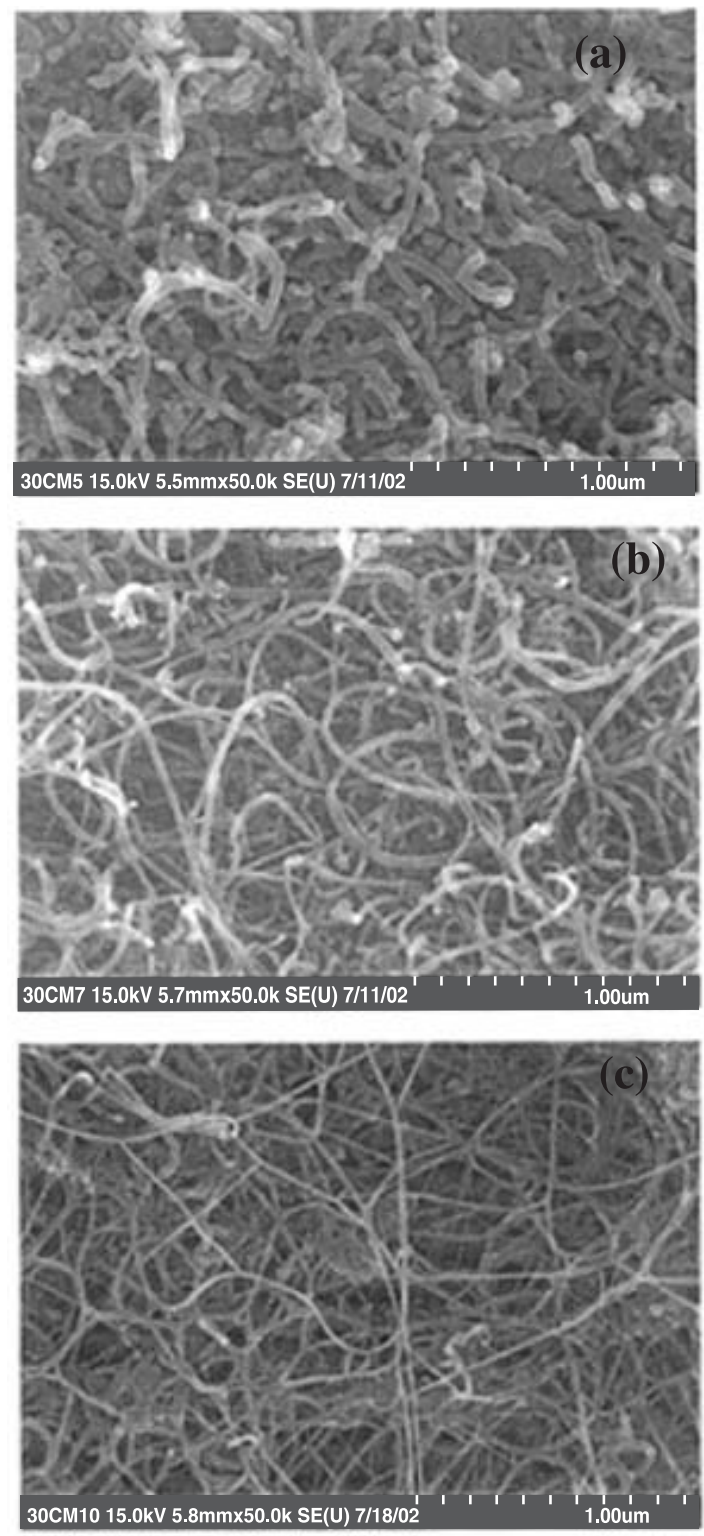

Fig. 1. SEM images of CNTs grown over 12Mo:18Co:70MgO catalyst for 30 minutes under 10/100 sccm $\mathrm{C}_{2} \mathrm{H}_{2} / \mathrm{H}_{2}$ flow at (a) 500, (b) 700 and (c) $900^{\circ} \mathrm{C}$ 500 to $700^{\circ} \mathrm{C}$ and then decreased 4.3 folds with further increase in temperature $200^{\circ} \mathrm{C}$. 
Figures 2(a)-(c) show the Raman spectra of the grown CNTs measured at the $\mathrm{Ar}^{+}$-laser excitation wavelength of $514.5 \mathrm{~nm}$. It can be seen that three common peaks are appeared in the spectra at around 1345, 1572 and 2690 $\mathrm{cm}^{-1}$, respectively. The first two peaks are associated with disordered carbonaceous products (Id) and tangential graphitized products (Ig), characteristic peaks for MWNTs (Kibria et al. 2001, Yudasaka et al. 1997). It can be seen that the Raman spectrum appeared for the CNTs grown at $500^{\circ} \mathrm{C}$ shows two distinct peaks at around 330 and $942 \mathrm{~cm}^{-1}$, respectively. The identification of these peaks and the reason of their appearance will be described later.

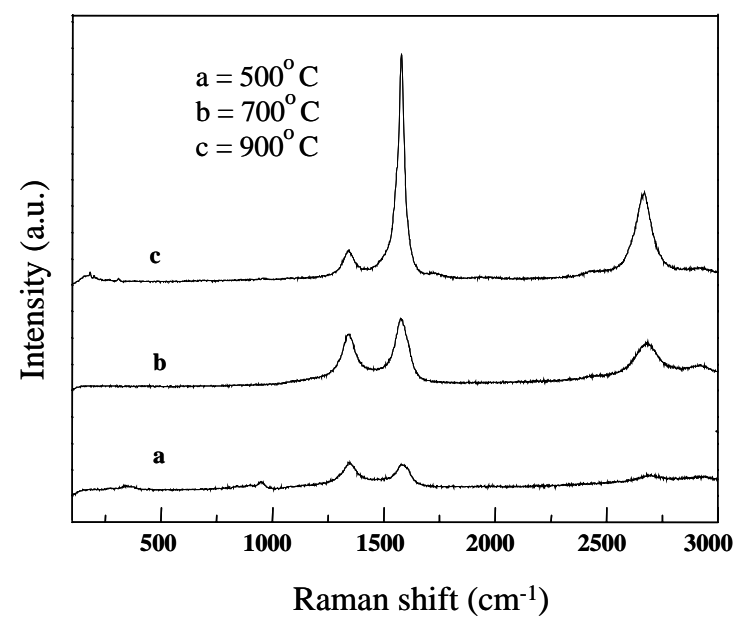

Fig. 2. Raman spectra for the CNTs grown over 12Mo:18Co:70MgO catalyst at (a) 500, (b) 700 and (c) $900^{\circ} \mathrm{C}$

Figures 3(a)-(c) show the QMS spectra for the species generated from $\mathrm{C}_{2} \mathrm{H}_{2}$ decomposition in $\mathrm{H}_{2}$ atmosphere over the catalyst at
500, 700 and $900^{\circ} \mathrm{C}$. The normalized peak intensity is expressed in mole fraction. Mole fraction is calculated by dividing the partial pressure of each species by operating pressure of QMS. The operating pressure of QMS was $5 \times 10-6$ Torr. It can be seen that peaks related to the species $\mathrm{C}, \mathrm{CH}, \mathrm{CH}_{4}, \mathrm{C}_{2}, \mathrm{C}_{2} \mathrm{H}$, $\mathrm{C}_{2} \mathrm{H}_{2}, \mathrm{C}_{2} \mathrm{H}_{3}, \mathrm{C}_{2} \mathrm{H}_{4}$ and $\mathrm{C}_{2} \mathrm{H}_{5}$ are appeared at $\mathrm{m} / \mathrm{e}$ values of $12,13,16,24,25,26,27,28$ and 29, respectively. It indicates that the used catalyst is capable to generate the required species $\mathrm{C}$ from $\mathrm{C}_{2} \mathrm{H}_{2}$ decomposition for the growth of CNTs at the experimental temperatures.

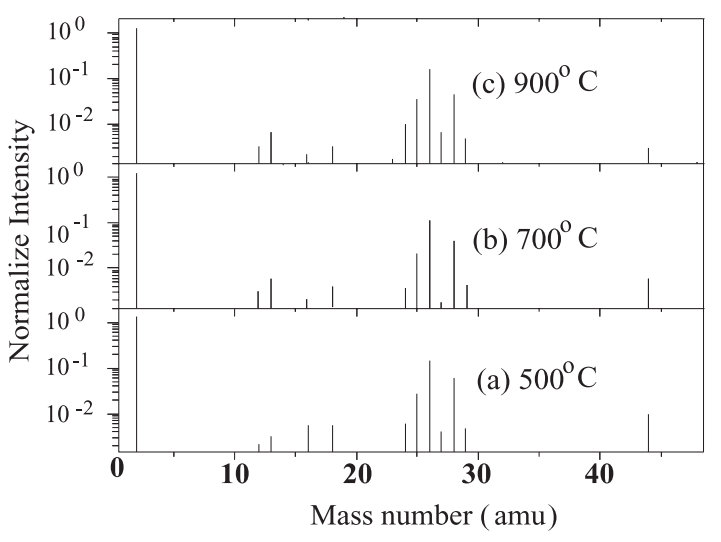

Fig. 3. Mass spectrum of the species formed during the decomposition of $\mathrm{C}_{2} \mathrm{H}_{2}$ over 12Mo:18Co:70MgO catalyst at (a) 500, (b) 700 and (c) $900^{\circ} \mathrm{C}$.

Figure 4 shows the variation of the partial pressure of $\mathrm{C}_{2} \mathrm{H}_{2}$ species as a function of time, with and without catalyst at 500, 700 and $900^{\circ} \mathrm{C}$, respectively. It can be seen that for the non-catalytic system, at a given 
temperature, the equilibrium of partial pressure attains quickly and it is higher compared to that of catalytic system. For the catalytic system, the slow attainment of partial pressure equilibrium of $\mathrm{C}_{2} \mathrm{H}_{2}$ species and lower partial pressure compared to those of noncatalytic system are the consequence of the activity of catalyst in $\mathrm{C}_{2} \mathrm{H}_{2}$ decomposition, i.e., the decomposition of $\mathrm{C}_{2} \mathrm{H}_{2}$ occurred via the 12Mo:18Co:70MgO catalyst.

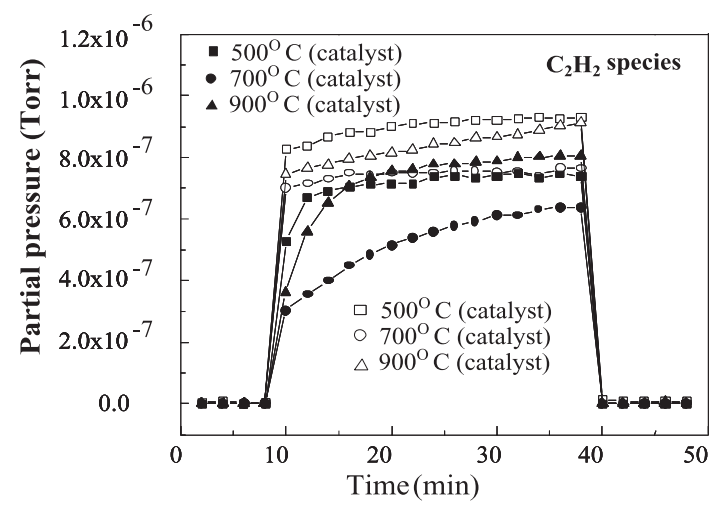

Fig. 4. Partial pressure vs. time plots for the $\mathrm{C}_{2} \mathrm{H}_{2}$ species with and without catalyst at (a) 500, (b) 700 and (c) $900^{\circ} \mathrm{C}$

Figure 5 shows the partial pressure vs. time trend for the $\mathrm{C}$ species in catalytic and noncatalytic conditions at different temperatures. It can be seen that the non-catalytic system attains quick equilibrium of partial pressure but for the catalytic system equilibriums seemed attain after 12, 35 and $20 \mathrm{~min}$ at 500, 700 and $900^{\circ} \mathrm{C}$, respectively. The consumption of $\mathrm{C}$ species up to the time of equilibrium attainment may be considered as the con- sequence of carbon yield, i.e., the production of CNTs. It is notable that carbon yield 7, 385 and $89 \%$ are observed at 500,700 and $900^{\circ} \mathrm{C}$, respectively. On the other hand, longest equilibrium achieving time and the highest yield of CNTs at $700^{\circ} \mathrm{C}$ may have a correlation with the abundance of the highest number of active particles to receive carbon fruitfully to grow CNTs.

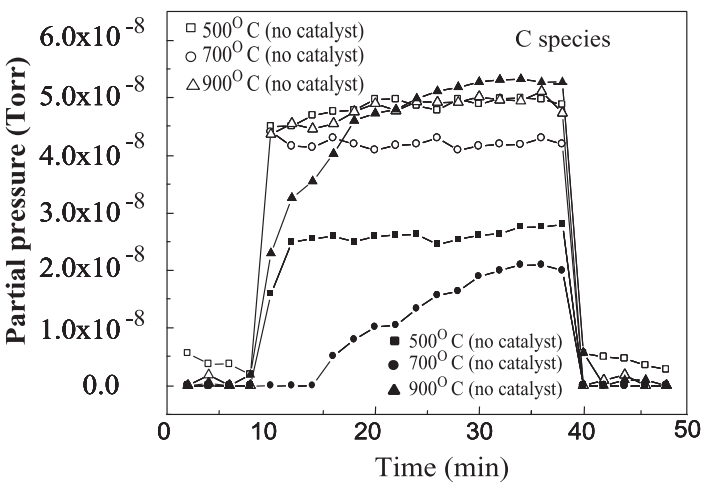

Fig. 5. Partial pressure vs. time plots for C species with and without catalyst at (a) 500, (b) 700 and (c) $900^{\circ} \mathrm{C}$

It has been reported that no tubes were grown over the 30Mo:70MgO catalyst. The catalyst 30Co:70MgO grown CNTs of 39\% carbon yield (Kibria et al. 2004). This report indicates that on addition of Mo with Co, favorable sized active metal particles to grow CNTs were enormously exposed to the catalyst surface by a phenomenon at $700^{\circ} \mathrm{C}$ during the growth stage. XRD analysis of the catalyst in different state and that of CNTs sample can be an informative of this phe- 
nomenon. Considering it, XRD analyses of the catalyst and CNT samples were carried out.

Figure 6(a)-(d) shows the X-ray diffraction (XRD) patterns of the support MgO, raw, calcined and reduced catalysts. It can be seen that XRD patterns of the calcined and reduced catalysts are different from that of raw catalyst but analogous to that of MgO. It represents the appearance of CoO-MgO solid solution (Radwan et al. 2003, Ullah et al. 2001, Wang and Ruckenstein 2002). The decomposition temperature of this phase is above $800^{\circ}$ C. For the raw catalyst, various sharp peaks are appeared at $2 \theta$ value of 18.6, 38, 51 and $58.8^{\circ}$, respectively. Up to $2 \theta$ value $40^{\circ}$, four weak peaks are observed at 12.5, 28.8, 33.3 and $35.4 \mathrm{o}$, respectively. The peaks indicate the appearance of $\mathrm{Co}_{3} \mathrm{O}_{4}, \mathrm{CoMoO}_{4}, \mathrm{MoO}_{3}$ and $\mathrm{Mg}_{2} \mathrm{Mo}_{2} \mathrm{O}_{7}$ (Radwan et al. 2003, Ullah et al. 2001, Wang and Ruckenstein 2002, Ning et al. 2002, Xiao et al. 2002). $\mathrm{CoMoO}_{4}$ species decomposes at around $550^{\circ} \mathrm{C}$ (Herrera et al. 2001). $\mathrm{MoO}_{3}$ reduces at around $1000^{\circ} \mathrm{C}$ (Radwan et al. 2003). So, no peak for Mo appeared at the XRD spectrum of the reduced catalyst. Although cobalt oxide reduces at $400^{\circ} \mathrm{C}$, it can partially consume by reacting with $\mathrm{MoO}_{3}$ and resulting $\mathrm{CoMoO}_{4}$ species ((Radwan et al. 2003). Moreover, very small amount of reducible $\mathrm{Co}_{3} \mathrm{O}_{4}$ species be appeared in $\mathrm{Co} / \mathrm{MgO}$ catalyst up to $600^{\circ} \mathrm{C}$ compared to unsupported $\mathrm{Co}_{3} \mathrm{O}_{4}$ (Ullah et al. 2001). It indicates that in the catalyst, the amount of reducible $\mathrm{Co}_{3} \mathrm{O}_{4}$ species was low.
The Co particles produced on reduction was small in size or in the form of cluster and highly dispersed over the catalyst surface. So, no diffraction peak for Co appeared in the spectrum of the reduced catalyst.

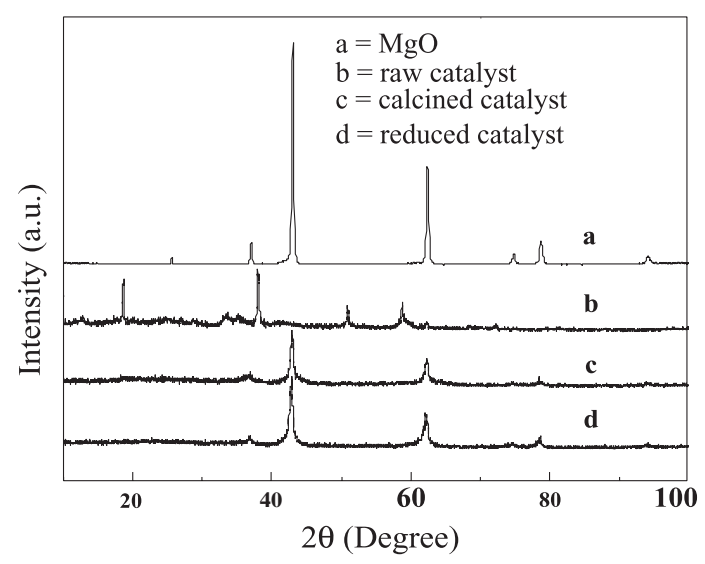

Fig. 6. XRD spectra of (a) support MgO, (b) raw catalyst, (c) oxide catalyst and (d) reduced 12Mo:18Co:70MgO catalyst.

Figure 7(a)-(d) shows the XRD spectra of the as-grown CNTs at $500,700,900^{\circ} \mathrm{C}$ and the reduced catalyst, respectively. It can be seen that except for the CNTs grown at $500^{\circ} \mathrm{C}$, a peak appeared at $2 \theta$ value of $26^{\circ}$ for the 002 graphite face of CNTs (Kibria et al. 2001). At $500^{\circ} \mathrm{C}$, the appearance of a hump peak at around $26^{\mathrm{O}}$ informs the growth of poorly graphitized tubes at this temperature. The value $\sim 1$ of the ratio of the intensities, $\left(\mathrm{I}_{\mathrm{d}} / \mathrm{I}_{\mathrm{g}}\right)$, of disordered carbonaceous product peak and tangential graphitized product peak obtained from Raman spectrum (Fig. 2) also informed the growth of poorly graphitized tubes at $500^{\circ} \mathrm{C}$. At $900^{\circ} \mathrm{C}$, the appearance of $\mathrm{Mo}_{2} \mathrm{C}$ 
peak at $39^{\circ}$ and Co peak at $44.5^{\circ}$ is suggesting the phase change of catalyst during the CNTs growth stage (Xiao et al. 2001).

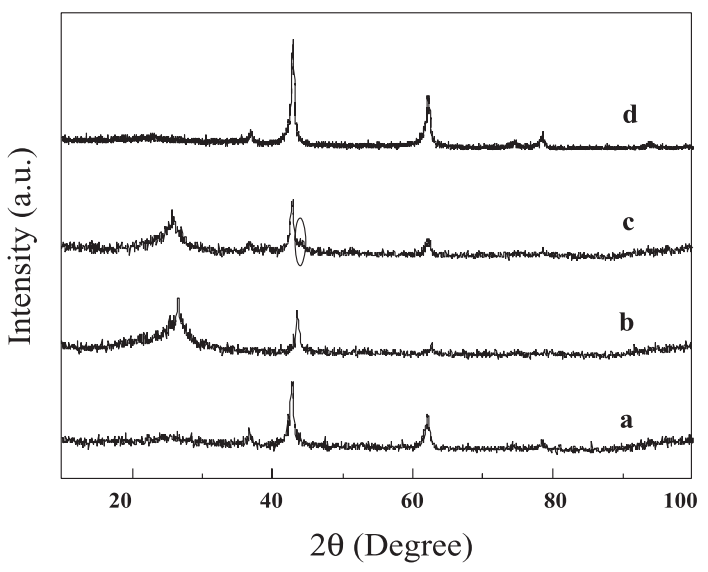

Fig. 7. XRD spectra of CNTs grown over 12Mo:18Co:70MgO catalyst at (a) 500, (b) 700 and (c) $900^{\circ} \mathrm{C}$ and (d) reduced 12Mo:18Co:70MgO catalyst.

In the Raman spectrum for the CNTs grown at $500^{\circ} \mathrm{C}$, the peak appeared at $942 \mathrm{~cm}^{-1}$ (Fig. 2) represents the appearance of undecomposed $\mathrm{CoMoO}_{4}$ species (Xiao et al. 2001). The absence of such a peak at higher than $500^{\circ} \mathrm{C}$, indicates that this phase was decomposed during the growth stage of CNTs. The cobalt oxide precursor released from the decomposition of this phase can easily be reduced to Co at 700 and $900^{\circ} \mathrm{C}$. In the Raman spectrum for the as-grown CNTs at $500^{\circ} \mathrm{C}$, the peak appeared at $330 \mathrm{~cm}^{-1}$ (Fig. 2) represents the appearance of $\mathrm{MoO}_{3}$. The disappearance of $\mathrm{MoO}_{3}$ peak at other temperatures indicates that $\mathrm{MoO}_{3}$ is rarely transforms to its carbide at $500^{\circ}$ C. This observation coincides with the findings of others (Xiao et al. 2002).

In the present case, the highest carbon yield achieved at $700^{\circ} \mathrm{C}$ which then decreased at $900^{\circ} \mathrm{C}$. The XRD spectrum of the as-grown CNTs samples showed a clear peak at $44.5^{\circ}$ for metallic Co at $900^{\circ} \mathrm{C}$, whereas such a peak was not appeared for the samples grown at the lower temperatures. It indicates that the size of Co particles increased after $700^{\circ} \mathrm{C}$. Particle size of Co increased by coalescence with the neighboring particles i.e., formation of agglomeration with increasing temperature. Authors (Wang and Ruckenstein, 2002) have reported a decrease in surface area of Co:MgO catalyst about 13 folds owing to coalescence of Co particles when the reduction temperature increased from 800 to $900^{\circ}$ C. In case of Co-Mo catalyst, the authors (Hada et al. 2002) observed more than 2.5 folds higher surface area while increasing temperature from 500 to $650^{\circ} \mathrm{C}$, but it then decreased about 4 folds owing to agglomeration of active metals on further increasing temperature to $800^{\circ} \mathrm{C}$. It can be speculated that the surface area of the catalyst increased at $700^{\circ} \mathrm{C}$ and then decreased with increasing temperature. The decrease in surface area corresponds to the appearance of larger particles and decrease in CNTs growth because the active metal particle size is a decisive factor to grow CNTs (Yudasaka et al. 1997).

It is not clear at this moment how the narrowest diameter CNTs grown at $900^{\circ} \mathrm{C}$. It seems that these tubes were originated from 
the active particles generated further in the catalyst at this temperature. It has been reported that the decomposition of $\mathrm{CoO}-$ $\mathrm{MgO}$ solid solution begins at above $800^{\circ} \mathrm{C}$. The released cobalt oxide can easily be reduced to metallic Co at this temperature. With increasing temperature, the decomposition of solid-solution phase highly increases and complete decomposition of it occurs at above $1000^{\circ} \mathrm{C}$ (Wang and Ruckenstein, 2002). So, it can be speculated that in the present case, the $\mathrm{CoO}-\mathrm{MgO}$ solid solution phase decomposed at $900^{\circ} \mathrm{C}$. The appearance of higher peak intensities at $900^{\circ} \mathrm{C}$ compared to those of reduced catalyst (Fig. 7) can be taken as an informative of it. Authors (Wang and Ruckenstein, 2002) have reported that the decomposition of $\mathrm{CoO}$ MgO solid solution and simultaneous reduction generates fine Co particles and Co clusters. These metallic Co and Co clusters seem responsible in growing narrowest diameter CNTs at $900^{\circ} \mathrm{C}$.

On compiling the XRD, Raman and SEM information, it can be said that the Co particles contributing in CNTs growth were generated form $\mathrm{Co}_{3} \mathrm{O}_{4}, \mathrm{CoMoO}_{4}$ and $\mathrm{CoO}-\mathrm{MgO}$ solid solution. The appearance of CNTs at $500^{\circ} \mathrm{C}$ indicates that the catalyst surface contained metallic cobalt in the form of cluster those were originated from $\mathrm{Co}_{3} \mathrm{O}_{4}$. At this temperature, very low carbon yield, i.e., about $7 \%$ indicates that the amount of Co cluster in the catalyst surface was very small (Ullah et al. 2001). It seems that at $700^{\circ} \mathrm{C}$,
Co cluster, and Co crystallites originated from $\mathrm{CoMoO}_{4}$ phase were participated in CNTs growth. At $900^{\circ} \mathrm{C}$, mostly the Co crystallites and clusters originated from $\mathrm{CoO}-$ MgO solid solution grown CNTs.

In the present case, the grown tubes are MWNTs. In a close look on the SEM images (Fig. 1), it can be seen that each tube ended by showing a white spot. These white spots originated from metal (Kibria et al. 2001). It indicates that CNTs were grown by tip growth mode. It means that the necessary carbon feed stock supplied from the catalytic decomposition of acetylene dissolved in metallic Co to form cobalt carbide eutectic, i.e., metastable cobalt carbide. This cobalt carbide eutectic on dissolving more carbon became oversaturated which then precipitated graphitic carbon in forms of tubes by keeping metallic cobalt cluster at the top end of the CNTs.

\section{Conclusions}

MWNTs were grown over 12Mo:18Co: $70 \mathrm{MgO}$ catalyst from the decomposition of $\mathrm{C}_{2} \mathrm{H}_{2}$. It was observed that growth density and diameter of CNTs are highly dependent on the growth temperature. Catalyst particle size controlled the CNTs growth. Quadruple mass spectroscopy (QMS) study identified that carbon species consumed during CNTs growth, and the consumption period of carbon varied with temperature. Carbon yield increased with increasing carbon consumption period. The Co particles participating in 
CNTs growth seemed originated from three precursors as $\mathrm{Co}_{3} \mathrm{O}_{4}, \mathrm{CoMoO}_{4}$ species and $\mathrm{CoO}-\mathrm{MgO}$ solid solution. The Co particles worked as the transporting medium of carbon to grow CNTs.

\section{Acknowledgements}

One of the authors is grateful to the Korean Science and Engineering Foundation (KOSEF) for granting him 'Brain Pool Scientist, Post-doctoral Fellowship to carry out this work in the Chonbuk National University, Republic of Korea. He is also grateful to Professor K. S. Nahm, Conbuk National University, South Korea, for his valuable suggestion and keen interest in this research.

\section{References}

Chatterjee, A. K. Sharon, M. Banerjee, R. and Spallart, M. N. (2003) CVD synthesis of carbon nanotubes using a finely dispersed cobalt catalyst and their use in double layer electrochemical capacitors. Electrochem. Acta 48 : 3439-3446.

Ci, L. Zhu, H. Wei, B. Xu, C. and Wu, D. (2003) Annealing amorphous carbon nanotubes for their application in hydrogen storage. Appl. Sur. Sci., 205(1-4) : 39-43.

Frackowiak, E. Gautier, S. Gaucher, H. Bonnamy, S. and Beguin, F. (1999) Electrochemical storage of lithium in multiwalled carbon nanotubes, Carbon 37(1) : 61-69.
Hada, K. Tanabe, J. Omi, S. and Nagai, M. (2002) Characterization of cobalt molybdenum nitrides for thiophene HDS by XRD, TEM and XPS. J. Catalysis 207(1) : 10-22.

Hafner, J. H. Bronikowski, M. J. Azamian, B. R. Nikolaev, P. Rinzler, A. G. Colbert, D. T. Smith, K. A. and Smalley, R. E. (1998) Catalytic growth of single-wall carbon nanotubes from metal particles. Chem. Phys. Lett., 296 (1-2) : 195-202.

Herrera, J. E. Balzano, L. Borgna, A. Alvarez, W. E. and Resasco, D. E. (2001) Relationship between the structure/composition of CoMo catalysts and their ability to produce single-walled carbon nanotubes by $\mathrm{CO}$ disproportion. J. Catalysis 204(1) : 129-145.

Kibria, A. K. M. F. Mo, Y. H. and Nahm, K. S. (2001) Synthesis of carbon nanotubes over nickel-iron catalysts supported on alumina under controlled conditions. Catal. Lett., 71(3-4): 229-236.

Kibria, A. K. M. F. Shajahan, Md. Mo, Y. H. Kim M. J. and Nahm, K. S. (2004) Long activity of Co-Mo/MgO catalyst for the synthesis of carbon nanotubes in large-scale and application feasibility of the grown tubes. Diamond and Related Mat., 13(13): 1865-1872.

Lee, T. Y. Han, J. H. Choi, S. H. Yoo, J. B. Park, C. Y. Jung, T. Yu, S. G. Yi, W. K. Han, I. T. and Kim, J. M. (2003) Effects of source gases on the growth of carbon nanotubes, Diamond and Related Mat., 12(3-7) : 851-855. 
Ning, Y. Zhang, X. Wang, Y. Sun, Y. Shen, L. Yang, X. and Tendeloo, G. V. (2002) Bulk production of multi-wall carbon nanotube bundles on sol-gel prepared catalysts. Chem. Phys. Lett., 366(5-6) : 555-560.

Otsuka, K. Kobayashi, S. and Takenaka, S. (2001) Catalytic decomposition of light alkanes, alkenes and acetylene over $\mathrm{Ni} / \mathrm{SiO}_{2}$. Appl. Catal. A: General 210(1-2) : 371-379.

Prosini, P. P. Pozio, A. Botti, S. and Ciardi, R. (2003) Electrochemical studies of hydrogen evolution, storage and oxidation on carbon nanotube electrodes. J. Power Sources. 118(1-2) : 265-269.

Radwan, N. R. E. Ghozza, A. M. and El-Shobaky, G. A. (2003) Solid-solid interactions in $\mathrm{Co}_{3} \mathrm{O}_{4}-\mathrm{MoO}_{3} / \mathrm{MgO}$ system. Thermochem. Acta 398 : 211-221.

Saito, Y. Hata, K. Takakura, A. Yotani, J. and Umemura, S. (2002) Field emission of carbon nanotubes and its application as electron sources of ultra-high luminance light-source devices. Physica B: Condensed Mat., 323 (14): 30-37.

Ullah, M. A. Spretz, R. Lombardo, E. Daniell, W. and Knozinger, H. (2001) Catalytic combustion of methane on $\mathrm{Co} / \mathrm{MgO}$ : characterization of active cobalt sites. Appl. Catalysis B: Environmental, 29 : 217-229.
Wang, H. Y. and Ruckenstein, E. (2002) Formation of filamentous carbon during methane decomposition over Co-MgO catalysts. Carbon 40 (11) : 1911-1917.

Xiao, T. C. York, A. P. E. Megren, H. A. Williams, C. V. Wang, H. T. and Green, M. L. H. (2001) Preparation and characterisation of bimetallic cobalt and molybdenum carbides, J. Catalysis 202(1) : 100-109.

Xiao, T. Wang, H. Da, J. Coleman, K. S. and Green, M. L. H. (2002) Study of the preparation and catalytic performance of molybdenum carbide catalysts with $\mathrm{C}_{2} \mathrm{H}_{2} / \mathrm{H}_{2}$ carburizing mixture. J. Catalysis 211(1): 183191.

Yu, K. Zhu, Z. Xu, M. Li, Q. and Lu, W. (2003) Electron field emission from soluble carbon nanotube films treated by hydrogen plasma, Chem. Phys. Lett., 373(1-2): 109-114.

Yudasaka, M. Kikuchi, R. Ohki, Y. Ota, E. and Yoshimura, S. (1997) Behavior of nickel in carbon nanotube nucleation. Appl. Phys. Lett., 70 : 1817-1822.

Received : October 21, 2004;

Accepted : June, 20, 2007 